http://www.jfas.info

\title{
THE EFFECT OF GROUP COGNITIVE-BEHAVIORAL THERAPY IN REDUCING AGGRESSION IN PATIENTS WITH THALASSEMIA
}

\author{
A. Kazemian ${ }^{1}$, M. Reza Ghorbani Mohammad Abadi*², F. Mahmoudi ${ }^{3}$ \\ ${ }^{1}$ MA of Personality Psychology, Islamic Azad University, Azad Shahr Branch \\ ${ }^{2}$ MA of Clinical Psychology -University of Medical Sciences North Khorasan \\ ${ }^{3} \mathrm{MA}$ of Educational Counseling
}

Published online: 15 February 2017

\begin{abstract}
The aim of this study was to investigate the effectiveness of cognitive-behavioral therapy (CBT) on aggression in patients with thalassemia. Methods: This is an applied study in terms of objective and it is semi-experimental due to the nature of the subject, pre-test, post-test and follow-up conducted in the control group. The sample consisted of 30 patients with thalassemia city in Bojnourd, they were selected by convenience sampling method and voluntarily participated in the study. The participants were randomly divided into two groups. The first group received cognitive - behavioral therapy and the second group received no therapy. Both groups were assessed by the pre-test, post-test, and one month follow up. The assessment tool in this study were Aggression Questionnaire AGQ. Data were analyzed using SPSS software and variance analysis with repeated measures.

Findings: the results showed that there is a significant correlation between the experimental group that received cognitive behavioral therapy and the control group that received no therapy in reducing aggression. These findings have important theoretical and clinical interventions. Conclusion: The results of this study will be to assess and validate detection and more precise controls used in the treatment of aggression in children with thalassemia in clinics. As well as services (CBT) to this group of clinical population as a nonpharmacologic (NMT) are effective.
\end{abstract}

Key words: cognitive behavioral group therapy, aggression, children with thalassemia

Author Correspondence, e-mail: Mohammadreza_ghorbani@yahoo.com doi: http://dx.doi.org/10.4314/jfas.v9i1s.730 


\section{INTRODUCTION}

Thalassemia is one of the most common diseases inherited chronic in the world that causes some problems such as lack of iodine al for patients, families and health systems. This disease is the most common hereditary disorder that almost can be seen in all races and the patients face with a variety of physical impairment during the treatment. Major thalassemia can be one of the largest chronic disorders in Iran because like any other chronic disease in addition to physical symptoms caused some social and psychological problems for patients and their family. Regular visits in hospitals and clinics all disrupts normal life and social and increases the psychological pressure and tension in the family. After diagnosing chronic illness, the family tries to cope with that. Most families successfully adapt with chronic illness of their children. In contrast, some of them may fail because of lack of access to accurate information about the disease and supportive resources adequate. Today, the most important developments in the field of medicine reduce deaths from thalassemia and increase the life expectancy of these patients, and their quality of life is concerned as one of the most important indicators of health care.

Since the treatment of psychological disorders caused by thalassemia is important to improve the life quality of patients and their family, some studies have been conducted to identify the psychological, social, and economic problems (Nasiri Tousi, 1997). Emotion is the mental, biologic, purposeful, and social phenomenon that emerges in the similar condition. Anger and aggression play an important role in human's life. Anger is an undesirable emotion with the most intensity which is characterized by incorrect thoughts and behaviors (Avril, 1983, Cassiono Sukhodolsky, 1995). Anger usually starts with an external stimulus, and often include a component blame (Cassino and Sukhodolsky, 1997).

People with high trait anger react more against an extensive set of stimuli (Spielberger, Rehirz and Seidman, 1995).

Thus, the overall structure is rooted in a human aggressive behavior. These are structures that can be made at the level of anger, hostility, physical aggression and verbal aggression. The dimensions of aggressiveness can provide the field of physical and psychological injuries. The results show that the aggressiveness is the most important indicators of psychological disorders such as conduct disorder and hyperactivity disorder (Derbi, Topin and Fortin, 1999, quoted by Kazemeini, 2010)

Anger and aggression are the most common symptoms in patients with brain damage. Assessments have shown that over 36 percent of children with thalassemia have reported 
feelings of anger and aggression, although, there is no full information in this field (Demarc and Gemini Hardt, 2001).

The results of this study show that children with thalassemia have problems in quality of life, especially in both physical and emotional disease, thus planning can increase the quality of life of these patients. The researcher tried using cognitive behavioral approach as clinical interventions, cognitive - behavioral therapy is a form of psychotherapy. Initially created to treat depression, but now many are used for mental illness. This therapy is used to solve the current problems and dysfunctional thinking and behavior changes. This name refers to the combination of behavior therapy and cognitive therapy. This therapy is based on the principles of behavior therapy and cognitive therapy is based. What is Behavioral Therapy? Therapies change dysfunctional behaviors with different ways. Cognitive therapy is also thought to lead to behavioral change. CBT is a combination of the two. More therapists use cognitive and behavioral methods to treat anxiety and depression in patients.

Those who founded this method and use acknowledge that probably irrational thoughts leads to psychological problems, but more likely dysfunctional behavior and stimuli by internal and external human environment are controlled. This study aimed to evaluate the effectiveness of cognitive - behavioral therapy (CBT) on aggression in children with thalassemia in 2016.

\section{METHODOLOGY}

This is an applied study in terms of objective and it is semi-experimental due to the nature of the subject, pre-test, post-test and follow-up conducted in the control group. The sample consisted of 30 patients with thalassemia city in Imam Reza (PBUH) in Bojnourd, they were selected by convenience sampling method and voluntarily participated in the study. The participants were randomly divided into two groups. The first group received cognitive behavioral therapy and the second group received no therapy.

In this study, descriptive and inferential analysis used to analyze data: Descriptive statistics include demographic characteristics and check the status of research variables using statistical tables and charts. Inferential statistics include Kolmogorov-Smirnov test to verify the normal distribution of data and analysis of covariance.

Design: This study is aimed to be applied and according to the merits of the quasiexperimental, pretest - posttest is selected in semi-experimental and control groups. The information could be useful for future research applications. As well as research method is correlation as one form of descriptive (non-experimental) methods. The study population: all patients (6-25) years with thalassemia in Imam Reza (PBUH) (the pursuit of archived records 
available), sample: sample size is considered based on Morgan and Krejcy in two equal parts the two groups. Also according to population size, simple random sampling method is used. Methods: In this study, educational package cognitive - behavioral therapy which is proportional to the ability of patients during meetings and timing of runs. The content of this course includes relaxation, assertiveness and group therapy are as follows:

Table1. Anger Control Training sessions by cognitive - behavioral therapy

\begin{tabular}{|c|c|}
\hline Descriptions & Sessions \\
\hline $\begin{array}{l}\text { Members express the concept of progressive muscle relaxation and familiarity of stress and } \\
\text { muscle for } 16 \text { groups, explanations about the importance of the present moment and being in the } \\
\text { here and now, explaining concept stress management and anger management for members using } \\
\text { several techniques, and learning to do everyday things, and keep the attention on them }\end{array}$ & First session \\
\hline $\begin{array}{l}\text { Progressive muscle relaxation and awareness to } 8 \text { muscle group, and exercise the body, a feeling } \\
\text { of physical and focusing on the breath }\end{array}$ & second session \\
\hline $\begin{array}{l}\text { Practice diaphragmatic breathing, progressive muscle relaxation for four muscle group, } \\
\text { visualization and relaxation to communicate thoughts and emotions }\end{array}$ & third session \\
\hline $\begin{array}{l}\text { Progressive muscle relaxation with imagery passive location-specific, negative thinking and } \\
\text { cognitive distortions and training }\end{array}$ & fourth Session \\
\hline $\begin{array}{l}\text { Their training provision, replacement, replacement of rational thoughts and self-talk and the } \\
\text { difference between logical and illogical steps }\end{array}$ & fifth meeting \\
\hline Autogenics practice, effective and dysfunctional coping, its definition and types & Sixth Session \\
\hline $\begin{array}{l}\text { Autogenics with their training and induction imagery, meditation sunlight with expressiveness } \\
\text { autogenics training }\end{array}$ & Seventh session \\
\hline $\begin{array}{l}\text { Meditation, mantra meditation practice and social support and planning for the future to continue } \\
\text { to use Horor techniques and extend them }\end{array}$ & Eighth Session \\
\hline
\end{tabular}

Sampling and data gathering was in the library method. In order to provide the necessary data resources for library print, online articles and relevant domestic and foreign literature study, the method used. For field data collection in order to complete the questionnaire in this study direct reference to the subject-field method is used. Data collection tools in this study included AGQ Buss-Perry Aggression Questionnaire (1992). The questionnaire consists of 30 questions with four option Likert scale $(0=$ never, $1=$ rarely, $2=$ sometimes, $3=$ always $)$ components of anger, aggression and malice are measured. AGQ Aggression Scale is a selfadministered scale Pencils. This questionnaire is developed by Arnold H. Buss and Perry in 1992. This 14-item questionnaire with 30 questions that the "anger", 8 questions "aggression" and eight other questions of "malice" measures. In this questionnaire, the participants 
answered the questions by selecting the options never, rarely, sometimes or always; and for each of the four options, the values $0,1,2,3$, and 4 are considered.

Except item 18 that has negative loadings to assess the reverse. The total questionnaire is evaluated from 0 to 90 . People who have scores lower than average have lower aggression and those who obtain the highest score of this test are more aggressive. Psychometric properties of the scale have been obtained by Zahedifar, Najarian and Shokrkon (2000). The pretest coefficients obtained between 0.64 and 0.79 scores twice and Cronbach's alpha coefficient equaled 0.87 . The validity of the questionnaire for children 10 years old that was calculated in 1996 by Najarian equaled 0.85. For adolescence (16 years), is validated by Allahyari in Iran. In this study, descriptive and inferential analysis used to analyze data: Descriptive statistics include demographic characteristics and check the status of research variables using statistical tables and charts. Inferential statistics include Kolmogorov-Smirnov test to verify the normal distribution of data and analysis of covariance.

Results: The aim of this study was to compare the effectiveness of cognitive behavioral group therapy in reducing aggression - thalassemic children in the city in Bojnourd. To organize the information obtained during the investigation, descriptive and inferential statistical methods were used; and the results can be seen in the following tables.

Table 2. Descriptive statistics of two groups

\begin{tabular}{|c|c|c|c|c|}
\hline Max. & Min. & SD & Mean & Age \\
\hline 25 & 10 & $31 / 6$ & $87 / 19$ & Examination group \\
\hline 24 & 10 & $14 / 6$ & 19 & Control group \\
\hline
\end{tabular}

According to the results that are presented in Table, mean and standard deviation in experimental group equaled 19.87 and 6.31, respectively, these scales in control group equaled 19 and 6.14, respectively.

Performance of the experimental group and the control group Aggression Questionnaire in the pre-test, post-test and follow-up offered. 
Table 3. The mean scores of two groups in aggression

\begin{tabular}{|c|c|c|c|c|c|}
\hline \multicolumn{2}{|c|}{ Control group } & \multicolumn{2}{|c|}{ Examination group } & \multicolumn{2}{|c|}{ Variable } \\
\hline SD & Mean & SD & Mean & & \\
\hline $04 / 12$ & $87 / 105$ & $39 / 9$ & $75 / 110$ & Pre-test & \\
\hline $82 / 11$ & $50 / 106$ & $61 / 16$ & $87 / 73$ & Post test & Aggression \\
\hline $30 / 12$ & $62 / 106$ & $83 / 0$ & $12 / 66$ & Follow up & \\
\hline
\end{tabular}

According to Table 2, the highest scores aggression (110.75) relate to the experimental group in pretest. As well as the lowest average scores of aggression (66.12) relate to the experimental group in post-test.

Table 4. The effect of test results between subjects related to aggression

\begin{tabular}{|c|c|c|c|c|c|c|}
\hline Effect & Sig. & F value & $\begin{array}{c}\text { Mean } \\
\text { squares }\end{array}$ & df & $\begin{array}{c}\text { Total } \\
\text { squares }\end{array}$ & $\begin{array}{c}\text { Source of } \\
\text { changes }\end{array}$ \\
\hline $60 / 0$ & $001 / 0$ & \multirow{2}{*}{$09 / 21$} & $25 / 2070$ & 1 & $25 / 2070$ & group \\
\cline { 4 - 7 } & & $12 / 98$ & 14 & $72 / 1373$ & Error \\
\hline
\end{tabular}

The results in Table 5 shows the effect of the subjects that the effects of the aggression between groups was significant $(\mathrm{P}<0 / 001)$. In other words, there was no significant difference between aggression scores in the experimental and control groups, so that the mean aggression in people who received cognitive behavioral therapy had significantly less aggressive than the average scores of the control group.

\section{DISCUSSION AND CONCLUSION}

Research on aggression management strategy for the general public who are faced with this problem show that there different ways to allow individuals to have control over their aggression. All patients with thalassemia in their ability to learn and develop new ways of living are consciousand there are reasons to believe that they can learn to control their anger and aggression and they can also express themselves socially acceptable. For this reason, it seems thatthe method is potentially useful for these people to help them improve the patients who have experienced similar problems and they make a practice to expand and provide new skills.

This study is one of studies that examine the effectiveness of interventions in controlling 
aggression in people with thalassemia and the results show the effectiveness of cognitive behavioral group therapy in reducing aggression - a sample of patients with thalassemia. The results were consistent with Sukhodolsky and colleagues (2001) who showed that cognitivebehavioral therapy is effective in reducing aggressive in driving.

In addition, research by Polizi (2007) has shown that mindfulness can reduce aggressive behavior in driving. Sadeghi and colleagues (1381) in reviewing the effectiveness of anger management training showed the effective method to control aggression with a sample of 24 high school students in Isfahan, in two groups $(\mathrm{n}=12)$ and control $(\mathrm{n}=12)$. The aggressive behavior of students reduced to take anger management training significantly. Hati and colleagues (1387) studied the effect of the training program combining cognitive - behavioral therapy with a positive approach on the prevention of juvenile violence in Tehran during a preliminary sample of 200 adolescents aged 13-14 years, 48 of them in the questionnaire aggression achieved highest score and achieved the lowest score in anger management questionnaire; they were randomly assigned to experimental and control groups The results showed that the combination of cognitive behavior therapy program with a positive approach reduces aggression in adolescents and helps them in anger management skills. The amount of aggression in boys was significantly higher than girls. In explaining aggression cognitive behavioral approach - these cases can be noted:

First, cognitive behavioral therapy is based on Beck's theory, and understanding "of Beck's theory has an important role in psychopathology. He believes that in such other aspects such as emotional aspects, behavioral and physiological aspects arising from this (Ghasemzadeh, 2008). Also, Beck (1975) believes that treatment should be started from the automatic thoughts; and in this study, identifying negative automatic thoughts, logical errors and negative core beliefs and behavior techniques and relaxation are emphasized and cognitive impairment cause that patients are taught more logical thinking skills, they learn to consciously reject negative thoughts (Ferry, 2005). The results achieved by Ansari, Borjali, and Hosseini al-Madani (2008) in a study on the effectiveness of cognitive behavioral therapy (CBT) on reducing the student's anger showed that cognitive behavior group therapy affects the anger reduction (overall).

They also found that this approach state anger, trait anger and anger decrease the frequency of determining the effectiveness of cognitive behavioral therapy in reducing anger and aggression, it can be said that anger and aggression is aroused by general muscle tension and arousal of the autonomic nervous system and endocrine activity and irrational beliefs about others. As it seems that this study is the first research done in the field of aggression cognitive 
- behavioral therapy in patients with thalassemia in Iran, in order to better understand the mechanism of this intervention, other research is needed. It is worth noting that this study was done in Imam Reza (PBUH) and the limitation of the study is target group that includes people with thalassemia recommended that cognitive behavioral approach is also done in other groups.

\section{REFERENCES}

[1] Ansari, Mojtaba, Borjali, Ahmad, Ahadi, Hassan, Hosseini al-Madani (2008). Evaluating the effectiveness of of cognitive-behavioral therapy (CBT) group on the reduction of student anger, Proceedings of the Fourth Seminar on mental health of students, Shiraz University.

[2] Hajati, Fereshteh Sadat, Akbarzadeh, Nasrin Khosravi, Zohreh (2008). The impact of cognitive behavioral therapy program combined with a positive approach on the prevention of juvenile violence in Tehran. Journal of Psychological Studies, Faculty of Education and Psychology Al, Vol. 4, No. 3, 57-78.

[3] Kazemi, Taktom (2010). Comparing the effectiveness of mindfulness-based cognitive therapy with cognitive behavioral therapy in reducing anger and aggressive driving, Master Thesis, Ferdowsi University of Mashhad.

[4] Mohammadi, Nourollah. (2007). A preliminary study of psychometric properties of Buss-Perry Aggression Questionnaire. Journal of Humanities and Social Sciences, Shiraz University, twenty-fifth, the fourth number, winter

[5] Navidi, Ahmad (2006). The impact of self-regulatory skills with anger, anger management training, public health compatibility and high school boys in Tehran. Doctoral thesis Allameh Tabatabai University in Tehran.

[6] Armbruster, M. A., Sukhodolsky, D. G., \& Michalsen, R. N. (2001). Impact of managed.

[7] Antonak, R. F., Livens, H. and Antonak, C. (1993) .A review of research on psychosocial adjustment to impairment in persons with traumatic brain injury. Journal of Head Trauma Rehabilitation, 8:87- 100.

[8] Averill, J. R. (1983). Studies on anger and aggression: implications for theories of emotions. American psychologist, 38, 1145-1160.

[9] Beck, A. T. (1975). Cognitive Therapy and the Emotional Disorders (New York, NY: International Universities Press). 
[10] Becker, G. (2007). The Buss-Perry Aggression Questionnaire: Some unfinished business. Journal of research in personality. Volume 41, Issue 2 April 2007, Pages 434-752.

[11] Novaco, R. W. (2013). Reducing anger-related offending: What works. In L. Craig, L. Dixon, \& T. Gannon EDs.). What works in Offender rehabilitation: An evidence-based approach to assessment and treatment. Chichester, UK: John Wiley \& Sons.

[12] Sukhodolsky, D. G.; Kassionve, H. \& Gorman, B. S. (2001). Cognitive behavioral therapy for anger in children and adolescent: A meta-analysis: Aggression and violent behavior, 9, 247-269.

\section{How to cite this article:}

Kazemian A, Reza Ghorbani Mohammad Abadi M, Mahmoudi F. The effect of group cognitive-behavioral therapy in reducing aggression in patients with thalassemia. J. Fundam. Appl. Sci., 2017, 9(1S), 768-776. 